\title{
EDUCAÇÃO CIENTÍFICA EM AÇÃO: A CARTOGRAFIA DE CONTROVÉRSIAS COMO PRÁTICA DE CIDADANIA TÉCNI- CO-CIENTÍFICA
}

\author{
SCIENCE EDUCACION IN ACTION: the controversy mapping as a practice of tech- \\ nical-scientific citizenship \\ EDUCACIÓN CIENTÍFICA EN ACCIÓN: el mapeo de controversias como práctica \\ de ciudadanía técnica y científica
}

\author{
Elisa Sampaio de Faria \\ Professora Mestre da Universidade Federal dos Vales do Jequitinhonha e Mucuri. \\ defaria.elisa@outlook.com
}

Francisco Ângelo Coutinho

Professor Doutor da Universidade Federal de Minas Gerais (UFMG).

fac01@terra.com.br

\begin{abstract}
RESUMO: A Educação em Ciências e os documentos oficiais que regulamentam a educação no Brasil relacionam fortemente a aquisição de conhecimentos científicos e a cidadania técnico-científica. Com o objetivo de instigar o debate sobre a educação científica para a cidadania, investigamos as conexões entre a participação cidadã e o conhecimento científico, na controvérsia sobre a instalação do Projeto Apolo na Serra do Gandarela, em Minas Gerais, Brasil. Tal polêmica mobiliza atores diversos: leigos, pesquisadores, políticos, empresas, recursos naturais, movimentos populares, entre outros. Diante da heterogeneidade dos participantes na disputa, fez-se necessário reunir ferramentas teóricas e analíticas que compartilhassem da perspectiva da ecologia política. O conjunto de ferramentas concebido para essa pesquisa foi fortemente fundamentado pela Teoria Ator-Rede (ANT). A ANT foi aliada à noção de cosmos e à proposta cosmopolítica, com grande contribuição do conjunto de ferramentas fornecido pela cartografia de controvérsias. Os resultados permitem concluir que a educação científica para a cidadania deveria investir na participação dos estudantes em questões técnico-científicas de interesse público e em práticas que abram espaços para as manifestações das multinaturezas dos objetos técnico-científicos.
\end{abstract}

PALAVRAS-CHAVE: Alfabetização científica. Cidadania. Teoria Ator-Rede. Cartografia de controvérsias. Multinaturalismo.

ABSTRACT: In recent years the Science Education is strongly related the acquisition of scientific knowledge as a prerequisite for technical-scientific citizenship. Aiming to provoke the debate about science teaching for citizenship, we investigate the connections between citizen participation and scientific knowledge in the controversy regarding the installation of the Apolo Project in Sierra Gandarela, Minas Gerais, Brazil. This controversy includes several actors, as: lay people, researchers, politicians, businessmen, natural resources, popular movements, etc. The heterogeneity of the participants in the dispute created the need for bringing together theoretical and analytical tools that share the perspective of political ecology. Therefore, the set of tools designed for this research was strongly founded by Actor-Network Theory (ANT). ANT was combined with the notion of cosmos and cosmopolitics proposed by Stengers and also with the mapping of controversy. The results show that science education for citizenship should focus on student participation in technic-scientific issues of public interest, and on practices that make room for the manifestations of the nature of technical and scientific objects.

KEYWORDS: Scientific literacy. Citizenship. Actor-Network Theory. Controversy mapping. Multinaturalism.

Artigo recebido em setembro de 2015

Aprovado em novembro de 2015

Cad. Pes., São Luís, v. 22, n. 3, set./dez. 2015 
RESUMEN: La Educación en Ciencias y los documentos oficiales que reglamentan la educación en el Brasil relacionan fuertemente la adquisición de los conocimientos científicos y la ciudadanía técnica y científica. Con el objetivo de provocar el debate sobre la educación científica para la ciudadanía, se investiga las conexiones entre la participación ciudadana y el conocimiento científico, en la controversia sobre la instalación del Proyecto Apolo en Sierra Gandarela en Minas Gerais, Brasil. Tal controversia moviliza actores diferentes: laicos, investigadores, políticos, empresas, recursos naturales, movimientos populares, entre otros. A frente la heterogeneidad de los participantes en la disputa, fue necesario reunir herramientas teóricas y analíticas que comparten la perspectiva de la ecología política. El conjunto de herramientas diseñadas para esta investigación fue basada fuertemente en Teoría del Actor-Red (ANT). La ANT se combinó con la idea de cosmos y la propuesta cosmopolítica, con gran contribución del conjunto de herramientas proporcionado por la cartografía de controversias. Los resultados muestran que la educación científica para la ciudadanía debería invertir en la participación de los estudiantes en cuestiones técnicas y científicas de interés público y en las prácticas que se pueden abrir espacios para las manifestaciones de multinaturalezas de objetos técnicos-científicos.

PALABRAS CLAVE: Alfabetización científica. Ciudadanía. Teoría Actor-Red. Mapeo de controversias. Multinaturalismo. 
EDUCAÇÃO CIENTÍFICA | Elisa Sampaio de Faria e Francisco Ângelo Coutinho

\section{1 | INTRODUÇÃO}

Embriões congelados nos tratamentos de fertilização, membros protéticos controlados pelo cérebro humano e a utilização de organismos geneticamente modificados na medicina e na agropecuária evidenciam o quanto as ciências e as tecnologias podem transformar as vidas das pessoas. Por essa capacidade de transformação, as decisões quanto à aplicação da ciência e tecnologia assumiram uma grande importância para as sociedades democráticas. Nesse contexto, a educação científica para a cidadania é discutida pela Educação como um importante objetivo a ser atingido, sendo também um objetivo declarado nos programas de educação científica na maioria dos países do mundo (BARRUE; ALBE, 2013; KOLSTØ, 2001).

Apesar da relevância assumida pela educação científica para a cidadania, não há consenso quando se toca na questão sobre como produzir competência para que as pessoas possam se posicionar sobre questões da ciência e tecnologia na arena pública (LATOUR, 2014). Na Educação em Ciências, há dissenso até mesmo quanto aos termos que melhor definem a educação científica preocupada com a formação cidadã. Sasseron e Carvalho (2011) apontam que os autores de língua espanhola costumam utilizar a expressão "alfabetización científica" para designar o ensino cujo objetivo seria a promoção de capacidades e competências entre os estudantes, capazes de permitir-lhes a participação nos processos de decisões do dia a dia. Nas publicações em língua inglesa, o ensino que compartilha do mesmo objetivo aparece sob o termo "scientific literacy". Laugkschs (2000) comenta que o termo "scientific literacy" é usualmente considerado sinonímia dos termos "public understanding of science", usado na Grã-Bretanha, e "la culture scientifique", utilizado na França. Sasseron e Carvalho (2011) também encontraram a expressão "alphabétisation cientifique" nas publicações francesas. Para pesquisadoras e pesquisadores cuja língua materna é a portuguesa, a tradução amplia a diversidade de termos. A expressão inglesa aparece traduzida como "letramento científico", enquanto as expressões francesa e espanhola significam literalmente "alfabetização científica". Esse parágrafo não pretende esgotar a diversidade de termos da Educação em Ciências que compartilham da cidadania como objetivo educacional, considerando que não há como se teorizar a questão de forma simplista, e que definições conceituais ostensivas pouco poderiam contribuir para o trabalho associado à educação científica para a cidadania.

Mais importante do que a terminologia utilizada para designar a educação científica para a cidadania é jamais confundi-la com o bom desempenho em uma prova. A educação científica para a cidadania deve ser compreendida como a participação e a contribuição de estudantes, com sabedoria, em assuntos técnico-científicos reais (VAN EIJCK; ROTH, 2010). Por isso, Van Eijck e Roth apontam que "o foco da educação científica para a cidadania deveria ser na participação de estudantes em atividades coletivas das quais a alfabetização científica emerge em um processo de aprendizagem distribuído, situado e dinâmico" (VAN EIJCK; ROTH, 2010, p. 192, tradução nossa).

Latour (2014) afirma que, para atuar como um cidadão em termos de ciência e tecnologia, é necessário aprender a delinear a assembleia em torno da questão, definir quais são os partidos envolvidos, quais são seus interesses e seus compromissos. Em outras palavras, é necessário aprender a mapear as questões técnico-científicas. Para mapear questões técnico-científicas, é preciso buscar dados com diversas ferramentas no maior número de fontes a que se conseguir acesso, perceber conexões, ler gráficos e tabelas, usar a intuição, farejar informações e, finalmente, se posicionar na arena da controvérsia.

O uso de ferramentas digitais tornou-se acessível e poderia ser utilizado para mapear as opiniões de especialistas, leigos, governantes e corporações, e também para desenhar as relações entre esses atores em torno de uma controvérsia (LATOUR, 2014). Todavia, houve e há ainda 
muito pouco esforço para equipar os cidadãos e estudantes com os novos instrumentos disponíveis para compreender as controvérsias técnico-científicas de uma maneira ajustada à situação presente. Além disso, não são empregadas energia nem inteligência suficientes para solucionar a forma como essas questões devem ser apresentadas para o julgamento público. Ou seja, a educação científica para a cidadania não deve estar estritamente relacionada a saber ciências, mas fortemente relacionada ao desempenho de ações cidadãs que incluam conhecimentos e objetos técnico-científicos.

$\mathrm{Na}$ Educação em Ciências, por exemplo, muito se debate sobre modelos de ensino, abordagem de questões sociocientíficas em sala de aula e enfoques curriculares (por exemplo, CARLETO; PINHEIRO, 2010; KOLSTØ, 2001; MONTEIRO; MONTEIRO, 2010; PIASSI, 2011; SASSERON; CARVALHO, 2011). Entretanto, é desafiador encontrar discussões sobre a utilização de novos instrumentos e ferramentas para apresentar questões técnico-científicas de uma maneira compreensiva que facilite a participação e a tomada de decisão por parte das cidadãs e cidadãos. Como resultado, existem muitos meios que envolvem os cidadãos em disputas técnico-científicas de interesse público, mas não há investimento no desenvolvimento de ferramentas por meio das quais essas questões possam ser compreendidas por todos os cidadãos interessados.

A pesquisa desenvolvida durante o mestrado da primeira autora teve como um de seus objetivos pensar em meios para que as questões técnico-científicas fossem mapeadas e apresentadas de forma compreensiva aos cidadãos interessados. De forma concomitante, buscou-se também identificar as conexões que a participação cidadã e o conhecimento científico estabeleciam em uma disputa técnico-científica, avançando na compreensão de como a alfabetização científica, no sentido apresentado por Van Eijck e Roth (2010), emerge em situações reais. Nesse artigo serão apresentados alguns dos resultados dessa pesquisa.

A controvérsia técnico-científica escolhida para ilustrar a pesquisa mencionada foi aquela desenvolvida em torno da possível instalação do Projeto Apolo, da Vale S.A., uma das maiores mineradoras do mundo, sobre aquíferos localizados na Serra do Gandarela, situada na Região Metropolitana de Belo Horizonte (RMBH), em Minas Gerais, Brasil. Tal polêmica mobiliza atores diversos, como: cidadãos leigos, pesquisadores, políticos, empresários, recursos naturais como a água, animais em risco de extinção, plantas endêmicas, grupos populares, ONGs, empresas, instituições públicas, entre outros.

\section{2 | REFERENCIAL TEÓRICO-ANALÍTICO}

Nesse trabalho, foram reunidas ferramentas teóricas e analíticas que compartilharam da perspectiva da ecologia política (LATOUR, 2004a), possibilitando a politização de questões relacionadas com o conhecimento técnico e científico, bem como a politização de atores não humanos e de práticas a eles relacionadas. Esse conjunto de ferramentas foi fortemente fundamentado pela Teoria Ator-Rede, com grande contribuição do conjunto de ferramentas fornecido pela cartografia de controvérsias (LATOUR, 2014; VENTURINI, 2010), e aportes da noção de cosmos e da proposta cosmopolítica de Stengers (2005). Esse referencial é ainda pouco conhecido pela Educação. Portanto, as seções seguintes introduzem e elucidam alguns dos conceitos básicos, essenciais para a compreensão dos resultados e conclusões da pesquisa que serão apresentados nesse artigo.

\subsection{A Teoria Ator-Rede}

Callon, Law e Latour desenvolveram, na década de 1980, uma abordagem que atendia à necessidade de uma nova teoria social, capaz de se ajustar aos estudos sobre ciência, tecnologia e sociedade, ao lidar com os objetos de uma maneira inovadora e diferente (LATOUR, 2012). Essa 
EDUCAÇÃO CIENTÍFICA | Elisa Sampaio de Faria e Francisco Ângelo Coutinho

abordagem ficou conhecida por Teoria Ator-Rede ou pelo acrônimo ANT, derivado de "Actor-Network Theory". Um dos seus grandes diferenciais é a maneira como compreende o "social".

Em oposição à tradicional compreensão do social como um conjunto homogêneo (LATOUR, 2012), a ANT o percebe "como um movimento peculiar de reassociação e reagregação" (LATOUR, 2012, p. 25). Assim, a concepção do social pela ANT ultrapassa a noção de domínio, de uma divisa com a "natureza" e toma a forma de "uma série de associações entre elementos heterogêneos" (LATOUR, 2012, p. 23). Nas palavras de Latour, o social

não designa um domínio da realidade ou um item especial; é antes o nome de um movimento, um deslocamento, uma transformação, uma translação, um registro. É uma associação entre entidades de modo algum reconhecíveis como sociais no sentido corriqueiro, exceto durante o curto instante em que se confundem. (LATOUR, 2012, p. 99).

Em síntese, a ANT conjectura cinco grandes incertezas (LATOUR, 2012):

a) a natureza dos grupos;

b) a natureza da agência dos atores;

c) os tipos de entidades que devem ser levados em consideração;

d) a natureza dos fatos;

e) os estudos realizados.

A incerteza sobre a natureza dos grupos se deve ao pressuposto básico de que "não há grupos, apenas formação de grupos" (LATOUR, 2012, p. 49). Ao observarmos o social, notaremos que os atores se relacionam com um ou outro grupo, em um processo infinito, constituído por laços frágeis e mutáveis. A cada momento, os atores podem estabelecer associações, bem como se afastar ou se desviar de outros atores. Essa incerteza favorece um trabalho empírico, afinal, "as formações de grupos deixam muito mais traços em sua esteira do que as conexões já estabelecidas" (LATOUR, 2012, p. 54) e geram um volume muito maior de dados do que um trabalho com grupos pré-estabelecidos.

A segunda incerteza é concernente à ação - objeto central das investigações na ANT - que "deve ser encarada como um nó, uma ligadura" (LATOUR, 2012, p. 72). A ANT considera que a ação é deslocada, distribuída e assumida, muitas vezes, por outros. Como resultado, o ator nunca está só ao agir. A ação é sempre partilhada, e é isso o que a expressão ator-rede busca enfatizar. $\mathrm{O}$ ator é aquilo que muitos outros levam a agir. Entretanto, a ANT alerta que não é porque a definição da fonte da ação é incerta que se deve recorrer a "explicações sociais" para esclarecê-la. A incerteza deve prevalecer sobre as tentativas de se interpretar sociologicamente as ações, para que os próprios atores possam indicar as entidades que atuam naquela realidade. Afinal, uma abordagem científica não deve obscurecer a informação precisa oferecida pelos dados, substituindo-a por aquilo que as pessoas não fizeram.

Para executar o trabalho de mapear as ações, é necessário perceber que elas são parte de um relato e nele aparecem como as "responsáveis por um feito" (LATOUR, 2012, p. 85), afetando um estado de coisas. Uma ação que não causa transformação não deixa traços, não entra no relato e não é considerada uma ação. Isso significa que um ator cujas ações não deixam traços em uma rede não está, de fato, atuando. Quando o ator realiza uma ação, ele atribui a ela "uma imagem, uma forma, uma roupagem, um corpo" (LATOUR, 2012, p. 86). À ação são atribuídos nomes e figuras.

A terceira incerteza é sobre os tipos de atores que devem entrar na dinâmica social. As habilidades sociais humanas básicas fornecem apenas um pequeno subconjunto de associações, muito aquém da totalidade formadora da sociedade. Em geral, todas as interações entre pessoas são integradas por objetos de algum tipo (LAW, 2012), como máquinas, leis, moeda, entre outros objetos. Por isso, sem heterogeneidade de atores, não haveria sociedade. Essa nivelação entre os tiposde atores que podem participar das associações recebe o nome de "princípio de simetria generalizada" (CALLON, 1986). 
É necessário perceber que a distribuição da capacidade de agência às coisas não significa igualá-las aos humanos. Latour esclarece que "humanos e objetos são nitidamente diferenciados. No entanto, uma diferença não é uma divisão" (LATOUR, 2012, p. 114). Suas diferenças não impedem a observação de como suas performances se misturam nos relatos.

A quarta incerteza sustenta que os fatos são sempre fabricados (LATOUR, 2012). Questões de interesse são altamente incertas, discutidas, controversas e interessantes, ao contrário das questões de fato. As questões de interesse podem ser mapeadas porque seus traços são encontrados em toda parte: nos jornais, na televisão e na internet, por exemplo. Conforme se desenvolvem, as questões de interesse podem eventualmente se tornar questões de fato - frias e rotineiras. Isso significa que os fatos existem em muitas formas diferentes e em variadas fases de realização; não importa se quentes ou frios: sempre são fabricados.

A última incerteza é quanto ao estudo a ser elaborado (LATOUR, 2012). As conexões sociais serão traçadas por meio da composição de relatos. Ou seja, ao construir o texto descritivo, a pesquisadora ou o pesquisador deverá inscrever as redes de performances dos atores investigados. Estando com a quarta incerteza em mente, ciente de que a fabricação não é o oposto de verdade, a tradicional finalidade da metodologia científica de se alcançar objetividade deve ser mantida no processo de redação. Almeja-se produzir textos que sejam ao mesmo tempo fabricados e acurados. Deve ficar claro que construído e real não são termos opostos, e que a questão é diferenciar as boas construções das ruins (LATOUR, 2004b). Logo, é imprescindível que o texto seja bem escrito, porque somente um bom texto poderá revelar a dinâmica social com exatidão e veracidade. Mas o que vem a ser um bom texto? Latour define um bom relato como "aquele que tece uma rede" (LATOUR, 2012, p. 189). A rede seria constituída por uma série de ações em que cada entidade deve ser tratada como um ator completo. O resultado disso será um relato, ou uma descrição, em que os atores fazem alguma coisa, ao se movimentarem, deslocarem e transformarem as entidades com quem se associam ou se dissociam.

Nas pesquisas da Educação em Ciências, transitam objetos das ciências naturais e da tecnologia que são também objetos da história, da política e da sociologia, tais como os medicamentos, a energia nuclear e os organismos geneticamente modificados. Ao conceber o social como um movimento e atribuir a ele uma heterogeneidade de atores, a ANT se apresenta como um referencial capaz de possibilitar que os objetos da ciência e da tecnologia sejam incluídos nas análises da Educação em Ciências. O mundo pesquisado passa a ser concebido como uma rede repleta de atores interconectados que podem ser, simultaneamente, dotados de propriedades humanas - como a capacidade da fala - quanto de propriedades das coisas - como a solidez típica das rochas (LATOUR, 1994). Portanto, nas pesquisas em Educação em Ciências fundamentadas na ANT, as entidades que poderão agir e, portanto, ser consideradas atores, são heterogêneas e não se limitam aos humanos.

\subsection{A Cartografia de Controvérsias}

As controvérsias emergem quando ideias, coisas e simplificações que costumavam ser aceitas começam a ser questionadas e discutidas (VENTURINI, 2010). Controvérsias são situações em que atores discordam e se iniciam quando esses atores percebem que não podem se ignorar mutuamente. A cartografia de controvérsias é o trabalho de arranjar dispositivos para explorar, descrever e visualizar controvérsias, especialmente aquelas de cunho técnico-científicas.

Na cartografia, a busca da objetividade deve se dar pela multiplicação de pontos de observação: "quanto mais numerosas e parciais são as perspectivas pelas quais um fenômeno é considerado, mais objetiva e imparcial será sua observação” (VENTURINI, 2010, p. 260, tradução nossa). 
EDUCAÇÃO CIENTÍFICA | Elisa Sampaio de Faria e Francisco Ângelo Coutinho

Por isso, pesquisadoras e pesquisadores devem utilizar o maior número possível de ferramentas de observação disponíveis, misturando-as sem restrições. Consequentemente, o conjunto de técnicas que a cartografia reúne não torna o processo de investigação mais leve. Pelo contrário, torna-o mais difícil, trabalhoso e vagaroso.

Uma ressalva deve ser feita: pesquisadoras e pesquisadores não podem fingir imparcialidade, já que, segundo a cartografia de controvérsias, as pesquisas nunca são imparciais (VENTURINI, 2010). Ainda que alguns pontos de vista ofereçam um panorama mais amplo, nenhuma observação escapa de um viés. A cartografia de controvérsias, portanto, não se vangloria de imparcialidade, mas demanda que seus praticantes apresentem outras parcialidades além da sua própria.

Para auxiliar a mudança de perspectiva na investigação, lentes de observação foram criadas. Essas lentes não dizem o que observar, mas levam a visão a diferentes camadas da controvérsia. Não devem ser compreendidas como uma série de perspectivas obrigatórias e muito menos exaustivas, mas são capazes de lembrar que uma observação minuciosa é impossível sem a sobreposição de uma variedade de camadas.

A primeira lente transporta a investigação de proposições a literaturas (VENTURINI, 2010). Ao se aproximar de qualquer controvérsia, a primeira impressão será, geralmente, a de uma caótica nuvem de proposições concorrentes. Por isso a tarefa inicial é mapear a teia de referências, revelando como os discursos dispersos são tecidos nos textos. Esse é o primeiro nível de articulação que a cartografia deve ser capaz de destacar.

Seguindo as teias de relações entre proposições polêmicas, é inevitável considerar as conexões que se espalham para além do universo textual (VENTURINI, 2010). As proposições são somente uma parte de grandes redes compostas de humanos, objetos, organismos naturais, entidades metafísicas e assim por diante. A segunda lente leva pesquisadoras e pesquisadores da literatura aos atores, porque os convida a dedicarem grande atenção a todos eles, não importando se são humanos, animais, objetos, ou qualquer outra coisa. Já a terceira lente transporta as investigadoras e investigadores dos atores para as redes. Para a ANT, não há um ator isolado. Os atores são sempre compostos e componentes de redes.

A quarta lente leva as investigações das redes para os cosmos. O termo cosmos inclui o sentido de harmonia e, ao mesmo tempo, o sentido de mundo (LATOUR, 2004a). Aqui, o termo remete ao uso atribuído por Stengers (2005) em sua proposta cosmopolítica, em que cosmos "se refere ao desconhecido, constituído por múltiplos mundos divergentes, e às articulações que eles poderiam, eventualmente, ser capazes de fazer, em oposição à tentação de uma paz que pretende ser definitiva e ecumênica" (STENGERS, 2005, p. 995, tradução nossa). Utopias podem ser compreendidas como cosmos na medida em que nos levam a "considerar esse mundo com outras perguntas, a ignorar as palavras de ordem que se apresentam como aproximadamente normais" (STENGERS, 2005, p. 998, tradução nossa).

A importância dos cosmos não deve ser subestimada. Os cosmos podem não aparecer como entidades reais na existência coletiva, mas isso não significa que não podem afetá-la (VENTURI$\mathrm{NI}, 2010)$. Como utopias, podem influir mais profundamente na configuração de redes do que qualquer análise realista. Essa lente lembra às investigadoras e aos investigadores que a ênfase colocada sobre a dinâmica das redes não deve leva-los a esquecer de que a maioria dos atores e grupos aspira a algum tipo de estabilidade. Portanto, será somente transitando de cosmos para cosmos que as investigadoras e os investigadores poderão perceber a extensão total das controvérsias que estudam (VENTURINI, 2010).

Stengers (2005) apresenta um caso concreto daquilo que, muitas vezes, permanece silenciado e deve ser trazido à presença. O exemplo trata da experimentação animal. Em laboratórios onde esses experimentos são realizados, existem normas, condutas, métodos e procedimentos muito 
EDUCAÇÃO CIENTÍFICA | Elisa Sampaio de Faria e Francisco Ângelo Coutinho

bem definidos para lidar com os animais, o que a autora denomina de "rito" (STENGERS, 2005, p. 997, tradução nossa).

O rito preenche as frestas e interstícios pelos quais a pergunta "o que eu estou fazendo?" poderia aparecer, tornando esse questionamento inoportuno e inconveniente. Também fazem parte de tal rito as grandes histórias sobre o avanço do conhecimento, a oposição entre a racionalidade e o sentimentalismo e as necessidades de submissão a um método. Esse conjunto de estratégias seria uma manobra para que pesquisadoras e pesquisadores possam manter distância da situação em que o animal é colocado. A existência do rito, portanto, atesta a necessidade daqueles que executam o experimento se protegerem, para simplesmente seguir os procedimentos. Para que uma decisão genuína sobre a experimentação animal seja tomada por parte desses pesquisadores e pesquisadoras, a situação a que o animal é submetido deve se ser exposta. Para trazer aqueles que podem ser vítimas dessa decisão à presença, seria necessário inventar restrições contra esses ritos. "O que o pesquisador ou pesquisadora decidiria por si mesmo (a), se estivesse ativamente livre das proteções que as decisões atuais parecem precisar?" (STENGERS, 2005, p. 997, tradução nossa). Esse questionamento nos leva à última e mais complicada lente da lista (VENTURINI, 2010).

A última lente leva o olhar da investigadora ou do investigador do cosmos para as cosmopolíticas (VENTURINI, 2010). A presença de "política" no termo cosmopolítica retira do cosmos a tendência de significar uma lista finita de entidades as quais devem ser levadas em conta no mundo, e a presença de "cosmos" retira da política a tendência de significar uma associação exclusivamente humana (LATOUR, 2004b). "Cosmos protege contra o encerramento prematuro da política, e política contra o encerramento prematuro do cosmos" (LATOUR, 2004b, p. 454, tradução nossa).

A cosmopolítica que Stengers (2005) apresenta não possui relação com a unificação dos cosmos em um único mundo. Por isso, a compreensão da proposta requer o abandono definitivo do mononaturalismo (LATOUR, 2004b), uma das ideias mais veneráveis da cultura ocidental: a crença de que por trás de todas as utopias e controvérsias deve existir uma realidade objetiva independente do que os atores imaginam, dizem ou fazem. O mononaturalismo pressupõe que a realidade objetiva poderia ser revelada através da ciência e do uso da razão, e o consenso seria naturalmente alcançado (LATOUR, 2004b; VENTURINI, 2010). Nesse sentido, a natureza seria um atalho para contornar as disputas políticas e atingir total harmonia. Seria uma questão de tempo até que todos fossem corretamente educados, e pudéssemos, finalmente, alcançar a paz definitiva. Por isso, a um dado momento, pensava-se que a ciência criaria o consenso e a harmonia, estendendo-se pela humanidade a ponto de que conflitos não fossem mais do que lembranças (LATOUR, 2004a).

Todavia, mesmo que às vezes um cosmos tenha prevalecido sobre o outro e as disputas tenham sido temporariamente silenciadas, jamais uma realidade ou convenção coletiva emergiu sem disputa na história da humanidade (VENTURINI, 2010). "A violência pacificadora das ciências define um único mundo comum, sem nos dar os meios, os intérpretes, as histórias, as redes, os fóruns, as ágoras, os parlamentos, os instrumentos, para compô-lo progressivamente" (LATOUR, 2004a, p. 354, tradução nossa).

A característica múltipla da proposta cosmopolítica se opõe ao mononaturalismo, e pode ser enfatizada pela expressão multinaturalismo, cunhada por Viveiros de Castro (1996) para designar um dos traços diferenciais do pensamento ameríndio. Enquanto o mononaturalismo se apoia na multiplicidade das culturas e na unicidade da natureza, o multinaturalismo supõe uma diversidade da natureza e uma unidade do sujeito. Todo o ser a quem se atribui um ponto de vista é um sujeito. Portanto, enquanto o mononaturalismo é multicultural, supondo uma diversidade de representações sobre uma mesma natureza externa, o multinaturalismo ameríndio propõe "uma unidade representativa ou fenomenológica puramente pronominal, aplicada indiferentemente sobre uma radical diversidade objetiva" (VIVEIROS DE CASTRO, 1996, p. 128). Isto é, os sujeitos, sejam eles humanos humanos ou não, compartilham universalmente da mesma condição humana, espiritual e cultural, 
EDUCAÇÃO CIENTÍFICA | Elisa Sampaio de Faria e Francisco Ângelo Coutinho

enquanto os corpos e a matéria seriam aquilo que é particular, tomando formas radicalmente diversas.

Da perspectiva da ANT, da ecologia política, das cosmopolíticas e do multinaturalismo as controvérsias não emergem por causa de diferenças entre opiniões (LATOUR, 2004b). As divergências que geram controvérsias são sobre a natureza das coisas, sobre o mundo em que vivemos. É necessário que se reconheça que as coisas agem, fazem agir e têm uma voz política (por vezes silenciadas por ritos) para que a paz possa ser construída (LATOUR, 2004a).

O conjunto de ferramentas teóricas e analíticas apresentado possibilita a politização de questões relacionadas com o conhecimento técnico-científico e de suas práticas que abrangem coisas. Esse conjunto de ferramentas conecta conhecimento técnico-científico e política. Com isso, oferece à pesquisa em Educação em Ciências a possibilidade de desenvolver sua atuação na politização de questões técnico-científicas e na democratização das decisões relativas a essas questões.

\section{3 | PROCEDIMENTOS ANALÍTICOS}

A mais longa etapa desse trabalho foi o estudo da literatura científica capaz de oferecer uma abordagem teórico-analítica, embasada na ecologia política. O resultado desse esforço foi a elaboração de um quadro teórico-analítico integrado por textos de Latour (1994, 2004a, 2004b, 2012, 2014), Callon (1986), Law (2011), Jasanoff (2012), Viveiros de Castro (1996), Stengers (2005) e Venturini (2010). O texto de Venturini trouxe orientações que facilitaram o desenho da investigação e nos possibilitou conhecer uma rede mundial de mapeamento de controvérsias que está em grande expansão desde a década de 1990. No Brasil, fazem parte dessa rede o Laboratório Pós-Disciplinar de Estudos da Universidade de São Paulo (ver trabalho realizado sobre a Educação por Santos et al., 2012), o MediaLab da Universidade Federal do Rio de Janeiro e o Laboratório de Estudos sobre Imagem e Cibercultura (Labic), da Universidade Federal do Espírito Santo.

O movimento seguinte consistiu no levantamento de textos, escritos ou orais, jornalísticos, científicos e literários que contivessem informações sobre o Projeto Apolo. O levantamento foi executado no maior número e variedade possível de fontes. A partir dos textos recolhidos, prosseguimos com a produção de um relato capaz de revelar a dinâmica da disputa sobre o Projeto Apolo de maneira acurada. O resultado obtido com esse trabalho foi um texto híbrido, em que questões técnicas, científicas, políticas e econômicas foram conectadas a interesses, incertezas, frustrações e mobilização popular. Finalmente, um diagrama foi produzido tendo como base esse longo e complexo relato, que evidenciou os movimentos de associações e dissociações mais relevantes para a conformação do Projeto Apolo. Esse diagrama foi inspirado no diagrama de translações de proposições proposto por Latour (2014). A seguir, apresentaremos esse diagrama.

\section{4 | DIAGRAMA DE TRANSLAÇÕES}

O diagrama de translações (Figura 1) foi construído com base nos principais movimentos de associação e dissociação tecidos pelo relato. Nele é possível observar, pelo movimento da linha em função do tempo e do eixo de dissociações e associações, o andamento da disputa sobre o Projeto Apolo de 2007 a 2014. Quão mais a linha se movimenta para a direita, no sentido das associações, mais o Projeto Apolo angaria aliados e caminha no sentido de se concretizar. Quando a linha regride no sentido esquerdo, o Projeto Apolo perde conexões na rede.

1 O relato completo está disponível na dissertação de Elisa S. de Faria (2014). 
Figura 1 - Diagrama de translações do Projeto Apolo.

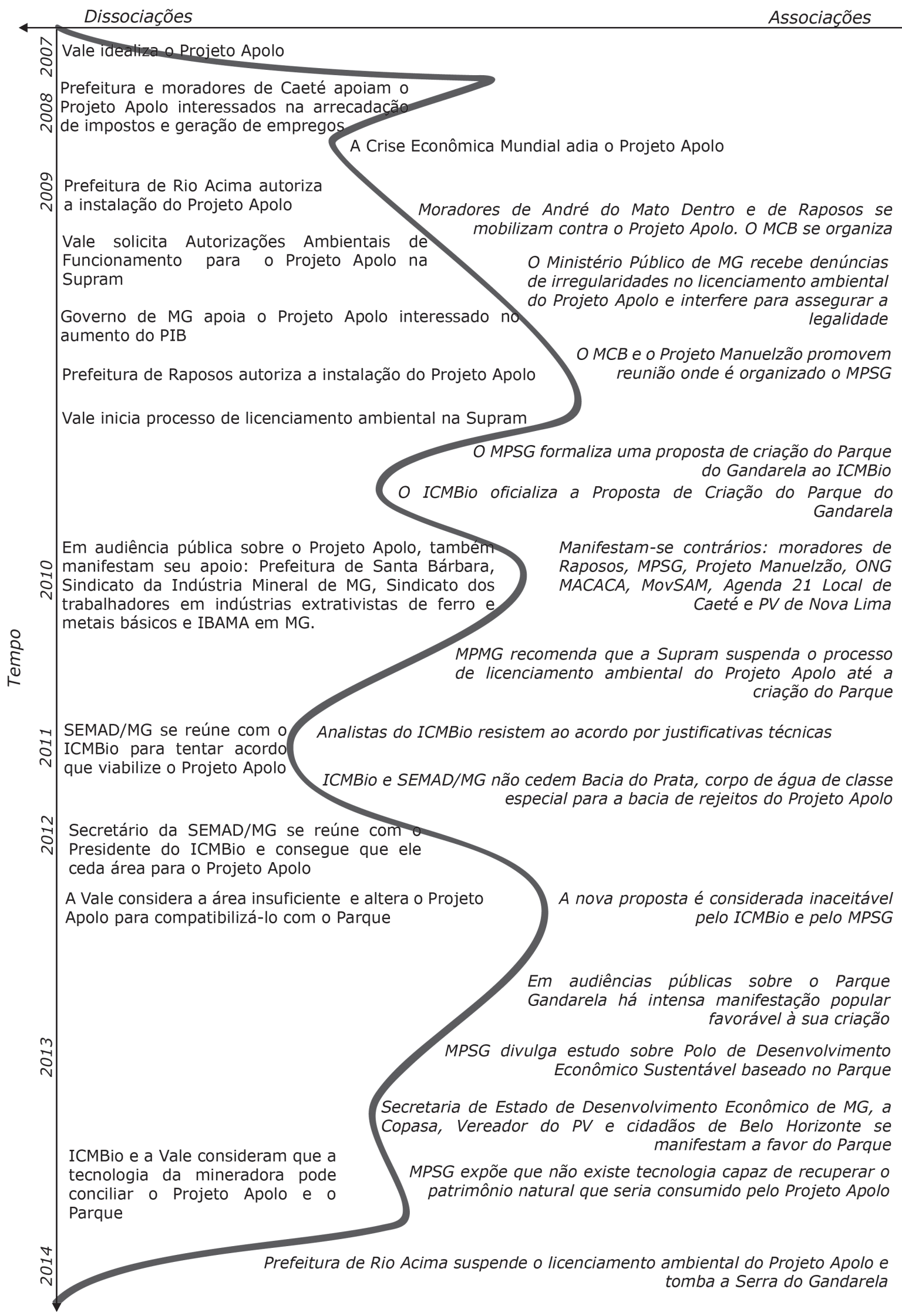

Fonte: Faria (2014), p. 115, adaptado pelos autores. 
Desde a sua origem até o ano de 2009, o Projeto Apolo conquistou aliados. Assim como a Vale, prefeituras de municípios mineiros e o Governo de MG interessavam-se nos ganhos financeiros que o Projeto iria proporcionar. Esse período foi marcado pela formação de um grupo interessado em grandes ganhos financeiros em curto prazo e pela forte atuação da Crise Econômica Mundial, que provocou o adiamento dos planos da mineradora. Somente no final de 2009, a empresa atuou para que o Projeto saísse do papel, ao solicitar Autorizações Ambientais de Funcionamento à Superintendência Regional de Regularização Ambiental Central Metropolitana (Supram).

Em 2009, começou a surgir um movimento popular contrário ao Projeto Apolo. Os moradores da região da Serra do Gandarela não queriam recebê-lo, por temer seus impactos. Denúncias de irregularidades no licenciamento ambiental foram recebidas pelo Ministério Público de Minas Gerais (MPMG). Movimentos populares, como o Movimento pela preservação da Serra do Gandarela, associaram-se a pesquisadores e a trabalhos científicos, para elaborar uma proposta de criação do Parque Gandarela. A proposta foi oficializada pelo Instituto Chico Mendes de Conservação da Biodiversidade (ICMBio) e conquistou cada vez mais aliados. É possível notar neste período a formação de um grupo interessado no desenvolvimento sustentável da Serra do Gandarela, tendo em vista a conservação de recursos naturais para as futuras gerações.

A partir de 2013, em fases mais recentes da controvérsia, o ICMBio se associou a instituições do Governo de MG e passou a utilizar o argumento de que a tecnologia da mineradora poderia mitigar os impactos sobre o patrimônio natural da Serra do Gandarela. Entretanto, o grupo interessado no Projeto Apolo possui interesse explícito de arrecadar dinheiro em um curto período de tempo, e nessa disputa, não possui práticas que demostrem interesse em qualquer tipo de desenvolvimento, a exceção do crescimento econômico bruto. Não foram encontrados indícios explícitos de que a Vale esteja investindo no desenvolvimento de conhecimentos técnico-científicos para conciliar seu interesse de arrecadar dinheiro, a partir da extração dos recursos naturais do Gandarela com o interesse, em grande parte silenciado, dos mais de 5 milhões de habitantes da RMBH de conservar os recursos ambientais dos quais sua sobrevivência, qualidade e modos de vida dependem das mais variadas maneiras.

O movimento ambientalista, por outro lado, permanece fomentando conhecimentos técnico-científicos fundamentados em um desenvolvimento que conserve e valorize as riquezas e patrimônios da região, como é o caso do estudo divulgado em 2013 sobre a viabilidade de um Polo de Desenvolvimento Econômico no Gandarela que, ao contrário do Projeto Apolo, pretende, de modo explícito, ser economicamente viável, ambientalmente correto, socialmente justo e culturalmente aceito. Além disso, o movimento prossegue conquistando aliados que acreditam em outros mundos possíveis, como a Prefeitura de Rio Acima. Todavia, o Projeto Apolo ainda persiste.

\section{5 | DISCUSSÃO DA ANÁLISE}

O diagrama permitiu observar que a aproximação da rede da controvérsia com o conhecimento científico foi realizada principalmente pelos movimentos populares ambientalistas, que reconheceram e utilizaram a ciência e a tecnologia como ferramentas políticas. Os resultados demonstram, portanto, que nessa rede é o movimento popular quem conecta o conhecimento técnico-científico à participação cidadã, fazendo emergir um hotspot de alfabetização científica: um espaço em que cidadãos e especialistas efetivamente se envolvem com a política coletiva e com a tomada de decisão pública sobre questões técnico-científicas (VAN EIJCK; ROTH, 2010).

Ainda, o diagrama de translações do Projeto Apolo pôde tornar claro como objetos técnico-científicos, quando compreendidos como sociotécnicos, são capazes de revelar as questões 
que acompanham a disputa técnico-científica, sejam elas políticas, sejam econômicas, afetivas, entre outras. Ao tornar explícito o desenvolvimento da rede de atores envolvidos na controvérsia do Projeto Apolo, o diagrama permitiu a politização de atores não humanos que, por meio de outras abordagens, poderiam permanecer silenciados. Esse foi o caso da água na Serra do Gandarela, que demonstrou estar ameaçada em sua disponibilidade e qualidade, ainda que seja recurso indispensável à vida.

O diagrama também possibilitou a visualização da formação de grupos e a exposição dos seus interesses que, de outra forma, poderiam ser obscurecidos. No caso dessa disputa, podemos ressaltar o interesse mercantil de um dos grupos que se sobrepõe à segurança hídrica da população da RMBH. Ficou claro que o grupo partidário do Projeto Apolo preconcebe um cosmos com duração pré-determinada - menos de duas décadas -, período em que o minério de ferro seria extraído, com o fim de produzir desenvolvimento econômico bruto. O grupo partidário da conservação da Serra do Gandarela, por outro lado, preconcebe um cosmos que inclui o modo de vida da população local e de suas gerações futuras, e também, a flora, a fauna e o abastecimento de água. Esse cosmos, mais rico em elementos, não possui duração determinada: opera em uma escala de tempo geológica e leva em consideração milhares de anos à frente.

Finalmente, a análise da disputa sobre o Projeto Apolo ofereceu pistas sobre as maneiras com que a ciência, a tecnologia e os especialistas se relacionam com a política em Minas Gerais e no Brasil. Em países ocidentais do continente europeu, as avaliações de especialistas são reconhecidas como autoridades legítimas por muitos dos agentes públicos (JASANOFF, 2012).

Convém ressaltar que, na disputa sobre o Projeto Apolo, as avaliações de especialistas não foram reconhecidas como autoridades legítimas por muitos dos agentes públicos e muitas vezes foram desconsideradas pelas autoridades políticas no processo de tomada de decisão. $\mathrm{O}$ relato sugere que as relações entre ciência, tecnologia, expertise e política no Brasil sejam profundamente diferentes daquelas observadas nos países ocidentais do continente europeu. Aqui, os interesses econômicos do Estado e de empreendedores são antepostos a pareceres de especialistas que sugerem cautela, prevendo danos ambientais irrecuperáveis e potencial ameaça de escassez de água, transformando profundamente o modo de vida de milhões de pessoas.

\section{6 | CONSIDERAÇÕES FINAIS}

A pesquisa, da qual decorre o presente artigo, se desenvolveu tendo em vista a educação preocupada com a formação da cidadania técnico-científica dos estudantes para sua atuação em questões de interesse público. Nesse trabalho, a educação científica para a formação cidadã na Educação em Ciências foi figurada principalmente pela alfabetização científica.

A história da cidadania é também a história das inovações que possibilitaram situações em que as pessoas têm uma opinião, fazem julgamentos, tomam decisões e as aceitam como sendo legítimas. O exercício da cidadania depende de objetos como as cédulas de votação. E a construção da cidadania técnico-científica depende de um esforço para se desenvolver instrumentos pelos quais as questões técnico-científicas de interesse público possam ser compreendidas e julgadas pelos cidadãos. Por isso, nesse trabalho avaliamos que a apropriação do princípio da simetria generalizada pela Educação em Ciências é proveitosa para a construção da cidadania técnico-científica, porquê confere capacidade de agência a ferramentas, procedimentos e dispositivos.

A disputa técnico-científica da instalação do Projeto Apolo, na Serra do Gandarela, foi mapeada e um diagrama de translações foi construído para explicitar o que está em jogo nessa disputa, incluindo questões que ultrapassam os detalhes técnicos da questão e evidenciando os grupos 
EDUCAÇÃO CIENTÍFICA | Elisa Sampaio de Faria e Francisco Ângelo Coutinho

envolvidos na controvérsia. Por isso facilitou a percepção de partidarismos e dos interesses dos grupos por parte dos estudantes e leigos.

Dessa maneira, espera-se que o uso do diagrama possa ser eficaz para possibilitar que as pessoas se informem e pensem sobre objetos técnico-científicos, como o Projeto Apolo. Espera-se também que o diagrama possa atuar como um dispositivo que aproxima estudantes e leigos das questões que estão associadas ao desenvolvimento de um projeto técnico-científico e ultrapassam o âmbito do conhecimento "puramente" científico. Espera-se, ainda, que o diagrama tenha reunido pontos de vista múltiplos, ao transitar pelos cosmos que habitam a disputa, e que seja reconhecida a capacidade de agência, bem como a política presentes em ferramentas e objetos da ciência.

Observamos os interesses de ganhos financeiros de um grupo e os interesses em conservação de recursos ambientais para as gerações futuras de outro grupo, esperando ter encenado uma ecologia política que, assim como enfatizou Stengers (2005), impeça que cidadãs e cidadãos imaginem que pessoas de bem irão decidir em nome do interesse comum, já que os dispositivos deixam explícito que não existe um interesse comum a todos os participantes dessa disputa, e que cada grupo busca a concretização de seu próprio interesse.

A questão cosmopolítica "Como fazer de um objeto técnico-científico algo para ser pensado?" é uma provocação para a pesquisa em Educação em Ciências. Para que objetos técnico-científicos sejam pensados, julgamos essencial o abandono da ideia de que controvérsias possam ser resolvidas mais naturalmente se as pessoas adquirirem conhecimentos, habilidades e valores sobre ciência e tecnologia. Essa ideia, como afirma Latour (2014), não é somente ingênua, mas também muito perigosa, ao passo que possuir conhecimentos científicos não desenvolve nada além de um envolvimento superficial com as controvérsias. O abandono dessa ideia pela Educação em Ciências seria mais difícil do que possamos imaginar. Significaria, em suma, eliminar o tão venerado mononaturalismo - pressuposto metafísico das ciências naturais -, e abrir espaço para as manifestações das multinaturezas dos objetos técnico-científicos. Assim, os objetos técnico-científicos podem ser entendidos como projetos técnico-científicos. Projetos são imbuídos de técnica, política, economia, afetividade, podendo ser, mais do que compreendidos, pensados.

O quadro teórico-analítico desenhado nesse trabalho constitui-se, portanto, como uma iniciativa para abandonar o mononaturalismo - um plano pedagógico de guerra - na Educação em Ciências, ao abordar uma disputa técnico-científica como uma guerra entre mundos. O relato e o diagrama do Projeto Apolo demonstraram que as divergências manifestadas na disputa não foram questão de opiniões, conhecimentos ou habilidades, mas sim, questão de divergências entre os mundos em que se quer viver.

Assim, pesquisadores poderiam investir energia e pensamento para investigar, desenvolver e experimentar objetos capazes de contribuir para a compreensão de controvérsias técnico-científicas por estudantes e leigos, na sala de aula ou fora dela, aproximando as pessoas das questões técnico-científicas que podem decidir seus mundos futuros.

O presente trabalho deixa questões a serem exploradas. Algumas delas seriam: A cartografia de controvérsias poderia atuar no sentido de transformar o curso da educação para a cidadania técnico-científica? Diagramas de translações contribuem para que leigos pensem e se posicionem sobre questões técnico-científicas de modo informado e não superficial? Como a cartografia de controvérsias poderia atuar em aulas de ciências, no sentido de fazer com que objetos técnico-científicos sejam pensados por professoras, professores e estudantes? A atuação desses objetos sociotécnicos poderia facilitar a participação daquilo que, assim como a água da Serra do Gandarela, em outras circunstâncias, não diria nada nas disputas? 
EDUCAÇÃO CIENTÍFICA | Elisa Sampaio de Faria e Francisco Ângelo Coutinho

Os trabalhos a serem realizados para responder a essas questões serão certamente árduos, complexos, dependentes de objetos e avançarão muito lentamente. A principal razão para tamanha dificuldade se deve a que pensar e fabricar inovações que considerem possível a construção de um mundo comum significa desenvolver ferramentas, dispositivos e procedimentos capazes de ampliar a participação cidadã, tornando a construção desse mundo comum mais trabalhosa e complexa. Significa, em um mundo onde impera um clima de urgência, criar espaços, para que se produzam interstícios, cultivar espaços para hesitações e ponderar constantemente que talvez haja algo mais importante. Finalmente, não podemos nos esquecer de que "um mundo comum, se é que haverá um, é algo que deveremos construir com unhas e dentes, juntos", e não "algo que venhamos a reconhecer, como se sempre estivesse aqui (e ainda não tivéssemos notado)" (LATOUR, 2004b, p. 455).

\section{Agradecimentos}

Os autores agradecem ao CNPq, à CAPES e à FAPEMIG o apoio financeiro. A primeira autora é grata à CAPES, pela bolsa de mestrado e o segundo autor é grato ao CNPq, pela bolsa de produtividade em pesquisa. 
EDUCAÇÃO CIENTÍFICA | Elisa Sampaio de Faria e Francisco Ângelo Coutinho

\section{Referências}

BARRUE, C.; ALBE, V. Citizenship education and socioscientific issues: implicit concept of citizenship in the curriculum, views of french middle school teachers. Science \& Education, v. 22, n. 1, p. 1089-1114, 2013.

CALLON, M. Some elements of a sociology of translation: domestication of the scallops and the fishermen of St Brieuc Bay. In: LAW, J. (Ed.). Power, action and belief: a new sociology of knowledge? London: Routledge, 1986. p. 196-223.

CARLETO, M. R.; PINHEIRO, N. A. M. Subsídios para uma prática pedagógica transformadora: contribuições do enfoque CTS. Investigações em Ensino de Ciências, v. 15, n. 3, p. 507-525, 2010.

FARIA, E. S. de. Cartografia de controvérsias: conexões entre o conhecimento científico e a disputa sobre a instalação do Projeto Apolo na Serra do Gandarela. 2014. 191 f. Dissertação (Mestrado em Educação)- Universidade Federal de Minas Gerais, Belo Horizonte, 2014. Disponível em: <http://hdl.handle.net/1843/bubd9q7eq7>. Acesso em: 17 maio 2015.

JASANOFF, S. The politics of public reason. In: RUBIO, F. D.; BAERT, P. The politics of knowledge. London: Routledge, 2012. p. 11-32.

KOLST $\varnothing$, S. D. Scientific literacy for citizenship: tools for dealing with the science dimension of controversial socioscientific issues. Science Education, v. 85, n. 3, p. 291-310, 2001.

LATOUR, B. Jamais fomos modernos. São Paulo: Ed. 34, 1994.

Políticas da natureza: como fazer ciência na democracia. Bauru: EDUSC, 2004a.

Reagregando o social: uma introdução à teoria do Ator-Rede. Salvador: EDUFBA; Bauru: EDUSC, 2012.

LATOUR, B. Week 7: how to become a citizen in the public life of science and technology? In: Massive open online course: scientific humanities. França: France Université Numeriquè, 2014.

Whose cosmos, which cosmopolitics? Common Knowledge, v. 10, n. 3, p. 450-462. 2004b.
LAUGKSCHS, R.C. Scientific literacy: a conceptual overview. Science Education, v. 84, n. 1, p. 71-94, 2000.

LAW, J. What's wrong with a one-world world. Middletown, Connecticut: Wesleyan University, 2011. Disponível em: <www.heterogeneities.net/publications/ Law2011WhatsWrongWithAOneWorldWorld.pdf>. Acesso em: 4 nov. 2013.

LAW, J. Collateral realities. In: RUBIO, F. D. ; BAERT, P. (Ed.). The politics of knowledge. London: Routledge, 2012. p. 156-178.

MONTEIRO, M. A. A.; MONTEIRO, I. C. C. Programa ReAção: uma análise das contribuições de uma pesquisa colaborativa com professores para a melhoria do ensino de ciências. Revista Brasileira de Pesquisa em Educação em Ciências, v. 10, n. 1, 2010.

PIASSI, L. P. Educação científica no ensino fundamental: os limites dos conceitos de cidadania e inclusão veiculados nos PCN. Ciência \& Educação, v. 17, n. 4, p. 789-805, 2011.

SANTOS, A.V. dos et al. Ensino superior indígena: mapeamento de controvérsias. 2012. Disponível em: $<$ http://ensinosuperiorindigena.wordpress.com>. Acesso em: 8 set. 2014 .

SASSERON, L. H.; CARVALHO, A. M. P. Alfabetização científica: uma revisão bibliográfica. Investigações em Ensino de Ciências, v. 16, n. 1, p. 59-77, 2011.

STENGERS, I. The cosmopolitical proposal. In: LATOUR, B. ; WEIBEL. P. (Ed.). Making things public: atmospheres of democracy. Cambridge MA: The MIT Press, 2005. p. 994-1003.

VAN EIJCK, M.; ROTH, W. M. Theorizing scientific literacy in the wild. Educational Research Review, v. 5, n. 2, p. 184-19, 2010.

VENTURINI, T. Diving in magma: how to explore controversies with actor-network theory. Public Understanding of Science, v. 19, n. 3, p. 258-273, 2010.

VIVEIROS DE CASTRO, E. Os pronomes cosmológicos e o perspectivismo ameríndio. Mana, v. 2, n. 2, p. 115-144, 1996. 